\title{
Highway Concrete (HWYCON) Expert System Requirements and Installation Guide
}

Lawrence J. Kaetzel

Building and Fire Research Laboratory

Gaithersburg, Maryland 20899

QC

100

.056

\#5190

1993

I V

United States Department of Commerce Technology Administration

National Institute of Standards and Technology 



\section{Highway Concrete (HWYCON) Expert System Requirements and Installation Guide}

Lawrence J. Kaetzel

\section{May 1993}

Building and Fire Research Laboratory

National Institute of Standards and Technology

Gaithersburg, MD 20899

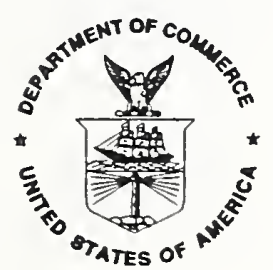

U.S. Department of Commerce

Ronald H. Brown, Secretary

National Institute of Standards and Technology

Raymond Kammer, Acting Director 



\section{CONTENTS}

Abstract

Disclaimer

List of Figures

vi

1. INTRODUCTION

2. USE OF HWYCON KNOWLEDGE

3. HWYCON KNOWLEDGE TOPICS

4. OPERATING THE HWYCON SUBSYSTEMS . . . . . . . . 3

4.1 Field Information Needed to Conduct a CONPAV-D Session . . . 3

4.2 Field Information Needed to Conduct a CONSTRUC-D Session . . 4

4.3 Information needed to Conduct a CONMAT Session . . . . . . 5

4.4 Information needed to Conduct a CONPAV-R Session . . . . . . . 5

4.5 Operating Commands . . . . . . . . . . . . . . . . . 5

4.5.1 Responding to questions . . . . . . . . . 5

4.5.2 HWYCON Conclusions and Recommendations . . . . . 8

4.5.3 Completing a session $\quad$. . . . . . . . . . . . . 8

5. DISTRIBUTION PACKAGE AND REQUIREMENTS FOR USING HWYCON . 8

6. INSTALLATION PROCEDURES . . . . . . 11

7. DE-INSTALLING PREVIOUS VERSIONS OF HWYCON $\quad$. . . . 14

8. PROBLEMS AND INCOMPATIBILITIES . . . . . . 15

8.1 Windows Version 3.1 Incompatibility . . . . . . 15

8.2 Other Problems Operating HWYCON . . . . . . . 15

9. REFERENCES . . . . . . . . . . . . . . . . . . . 16

APPENDIX A. FIELD CHECKLISTS FOR CONPAV-D AND CONSTRUC-D . 17 


\begin{abstract}
A computerized system that contains knowledge about materials related activities for highway concrete structures has been developed. The system, named HWYCON (HighWaY CONcrete), was developed by the National Institute of Standards and Technology in Gaithersburg, MD. HWYCON was developed for the Strategic Highway Research Program's Project C-206, "Optimization of Highway Concrete Technology". The knowledge contained in HWYCON consists of facts, rules of thumb, photographs, drawings, and bibliographic references. The system is designed to assist highway departments in diagnosing distresses, selecting materials, and making repair and rehabilitation decisions related to highway concrete pavements, bridge decks, and bridge substructures. This document was written to identify the contents of the HWYCON implementation package, and to provide information on the requirements and installation of the computerized system.
\end{abstract}

Keywords: Building Technology, concrete materials, expert system, highway concrete, HWYCON, Strategic Highway Research Program. 


\section{DISCLAIMER}

The reference to specific names of computer equipment and software programs are provided to give users instructions on the requirements for installing and operating the HWYCON computerized system. The references do not constitute an endorsement by the National Institute of Standards and Technology. 


\section{List of Figures}

Figure 1. Example of a HWYCON question and answer screen . . . . . . . 6

Figure 2. Example of a HWYCON explanatory information screen . . . . . . 7

Figure 3. Example of a CONPAV-D conclusion screen . . . . . . . . . . . . 9 


\section{INTRODUCTION}

HWYCON is product number 2039 of the Strategic Highway Research Program (SHRP), C-206 Project, on the "Optimization of Highway Concrete Technology". The computerized system was developed by the National Institute of Standards and Technology (NIST), in Gaithersburg, MD. NIST performed as a subcontractor to CTL, Inc., Skokie, Illinois. HWYCON is designed to assist highway staff in diagnosing distresses, selecting materials, and making decisions regarding repair and rehabilitation of highway structures. The system's focus is on materials related knowledge for concrete pavements, bridge decks, and bridge substructures. The computerized system is a decision making tool to assist inspectors, engineers, concrete materials specifiers, and other decision makers.

This document identifies the topics covered by the HWYCON system, provides installation and operating instructions. It is written for the user of the computerized system. Detailed information on the architecture, development, implementation, and guidance on how to modify HWYCON is described in a separate document titled, "High $\underline{\mathbf{W}} \underline{\mathrm{Y}}$ CONcrete" (HWYCON) User Reference and Enhancement Guide"[Kaetzel, Clifton, Snyder, Klieger 1993]," which is provided with the computerized system.

\section{USE OF HWYCON KNOWLEDGE}

HWYCON's conclusions and recommendations are meant to be used as a decision making tool. The final responsibility for any decision lies with the user. Although the system contains facts and rules-of-thumb from leading experts in the field of concrete, it is important to understand that variations can occur in the perception of the structure's performance and condition; the misstatement of the observer or absence of information may make a recommendation invalid. Users are encouraged to conduct the tests and procedures recommended by the system. Also, standard test methods should be used in the prediction and measurement of performance of materials. If a result is inconclusive after all tests and procedures have been exhausted, an expert familiar with the knowledge topic should be consulted.

\section{HWYCON KNOWLEDGE TOPICS}

HWYCON knowledge is contained in 3 subsystems; 1) Concrete pavement, bridge deck, and bridge substructure diagnostics (CONPAV-D, and CONSTRUC-D), 2) concrete materials selection (CONMAT), and 3) concrete pavement repair and rehabilitation (CONPAV-R). The specific knowledge areas covered in each of the subsystems is listed below. A detailed description is provided in the "Highway Concrete (HWYCON) User Reference and Enhancement Guide"[Kaetzel, Clifton, Snyder, Klieger 1993] supplied with the computerized system. The specific categories represented in HWYCON are: 
CONPAV-D (Concrete Pavement-Diagnostics)

- JRCP, JPCP, and CRCP type pavements

- common distresses that occur in slabs, at joints, and slab surfaces

- distresses that display the following symptoms:

- cracking

- sealant failures

- spalling

- popouts

- punchouts

- scaling

- polishing of aggregate

- potholes

CONSTRUC-D (Concrete Structures-Diagnostics)

Bridge Decks

- Sub-structure (columns, piers, parapet walls, etc.)

- distresses that display the following symptoms:

- cracking

- spalling

- popouts

- disintegration and scaling

- polishing of aggregate (bridge decks)

CONMAT (Concrete Materials Selection)

- Alkali-aggregate reactivity

- Corrosion of reinforcing steel

- Freezing and Thawing Action

- Sulfate attack

- Fast Track Concrete

- Permeable bases

- Recycling concrete

CONPAV-R (Concrete Pavement Repair and Rehabilitation)

- Full-Depth Repair materials and procedures

- Partial-Depth Repair materials and procedures

- Bonded Overlay materials and procedures

- Unbonded Overlay materials and procedures

- Diamond Grinding and Milling materials and procedures 


\section{OPERATING THE HWYCON SUBSYSTEMS}

Operating the HWYCON subsystems requires the following steps:

1. starting the computer

2. starting Windows

3. selecting the "HWYCON Expert System" window

4. selecting (clicking) an icon to activate the desired subsystem

5. conducting a session

6. terminating a HWYCON and returning to the Windows program manager.

When a HWYCON icon is selected, a command is processed to load the selected HWYCON computer program and knowledge base. Each program begins by displaying identifying information, start options, and help facilities. The user must select the "start session" push button to begin a session. When sufficient information has been obtained from the user (through a series of question-and-answer screens), a screen containing a conclusion or recommendation is displayed. At this point, the user may chose to view additional explanatory information, restart the session, repeat the same session (with different questions), or quit HWYCON, and return to the Windows Program Manager.

HWYCON will ask questions involves conditions observed in the structure, its environment, and its history. To assist the user in this procedure, checklists for concrete pavements, bridge decks, and bridge substructures field inspection are provided in Appendix A. These will be useful when a desk top computer is used. They will not be necessary when portable computers are used in the field. To help the user become familiar with the types of information needed by HWYCON, a list of the knowledge topics is provided in the following sections.

\subsection{Field Information Needed to Conduct a CONPAV-D Session}

In order to answer the questions posed by CONPAV-D, you should have the following applicable information available about the pavement (examples are shown):

- the type of concrete pavement

- Jointed Reinforced Concrete Pavement (JRCP)

- Jointed Plain Concrete Pavement (JPCP)

- Continuous Reinforced Concrete Pavement (CRCP)

a the location of the distress

- within the slab

- at joints

- at the surface

for symptoms that involve cracking, the crack pattern, direction, and width

- transverse cracking 
- longitudinal

- cracks at edges, openings

- straight crack(s)

- map or cluster cracks

for certain distresses, it will be helpful to know any history of aggregate reactivity, or sulfate attack that has occurred locally, and the type of aggregate used, such as carbonate/dolomite, or siliceous rock

other symptoms related to the pavements visual appearance such as rust staining, will also be helpful

\subsection{Field Information Needed to Conduct a CONSTRUC-D Session}

\section{Bridge Decks:}

The following information may be needed to operate the CONSTRUC-D (bridge deck) sub-system. Some items depend on the type of distress selected.

Type of bridge construction (concrete or steel and concrete)

Existence of epoxy coated reinforcing bars

- The exposure of the bridge deck to: freezing temperatures, chloride ions, or sea water

The distress type

Crack direction, pattern, location, depth, and width

- Popout dimensions

Age of crack

\section{Structures:}

The following information may be needed to operate the CONSTRUC-D (Structures) sub-system.

Structural element (e.g. slab, pier)

Distress type (e.g. cracking, spalling)

Distress location (e.g. vertical, horizontal surface)

- Crack pattern, width, depth, direction

Exposure conditions (e.g. freezing temperatures, soil or sea water)

Evidence of overall expansion

Whether the concrete is air entrained

$\square \quad$ Age of cracks

- Popout dimensions 


\subsection{Information Needed to Conduct a CONMAT Session}

durability area or procedure for designing the concrete
past record or performance of materials based on test methods
type of material to be used in specifying the concrete
exposure conditions
required opening time for project
type of permeable base
type of construction (e.g. reinforced or plain concrete pavement)

\subsection{Information Needed to Conduct a CONPAV-R Session \\ 口 procedure to be used (e.g. full-depth repair, bonded overlay) \\ - information type (e.g. recommendations on materials or procedures) \\ required opening time}

Only that information that is relevant to the structure being evaluated will be asked during a user session.

\subsection{Operating Commands}

\subsubsection{Responding to questions}

The format of a HWYCON session consists of a question and answer dialog between the computerized system and the operator. Operating HWYCON involves pointing to an area (e.g. push button, response to a question) of the screen, and clicking the left-hand mouse button. No typed commands are required to operate the system. There will be more than one possible response to a question, and the user should select the single best choice (in some cases, multiple choices may be selected) that best answers the question. Many question and answer screens contain PICTURE, DRAWING, and EXPLAIN push buttons. When selected, these push buttons display digitized photographs of distresses, drawings of distresses and procedures, and explanatory information, respectively. To return to the previous question and answer screen from a PICTURE, DRAWING, or EXPLAIN screen, the GO BACK push button is provided. The user must select the ENTER push button to record the choice(s) selected from the question and answer screen. An example of the HWYCON question and answer screen is illustrated in Figure 1. An example of an explanatory screen is illustrated in Figure 2.

Help facilities are available at the start of each HWYCON subsystem. The topics covered in the help facilities include; 1) information needed to use the subsystem, 2) use of push buttons, and 3 ) bibliographic references. 


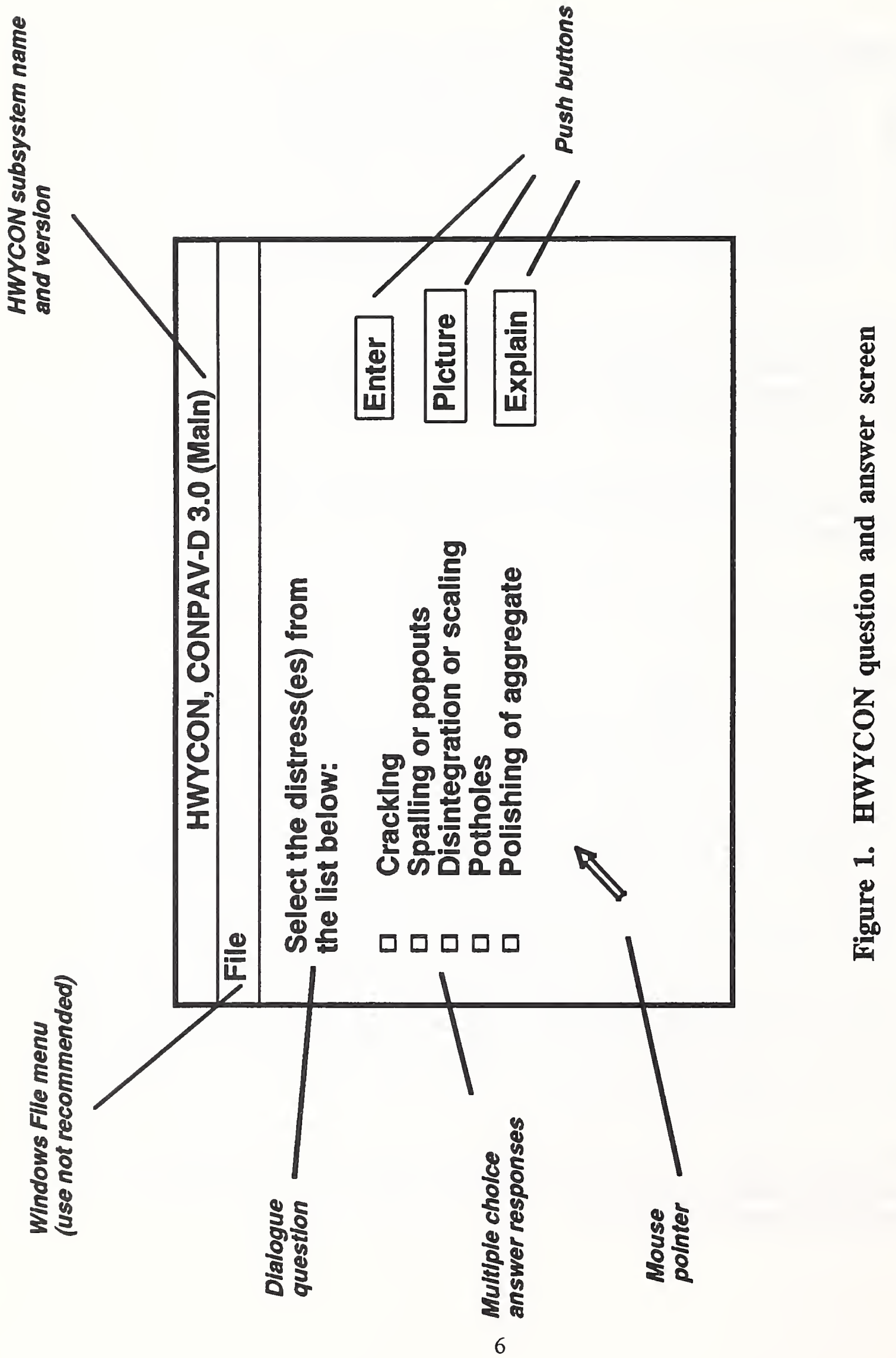




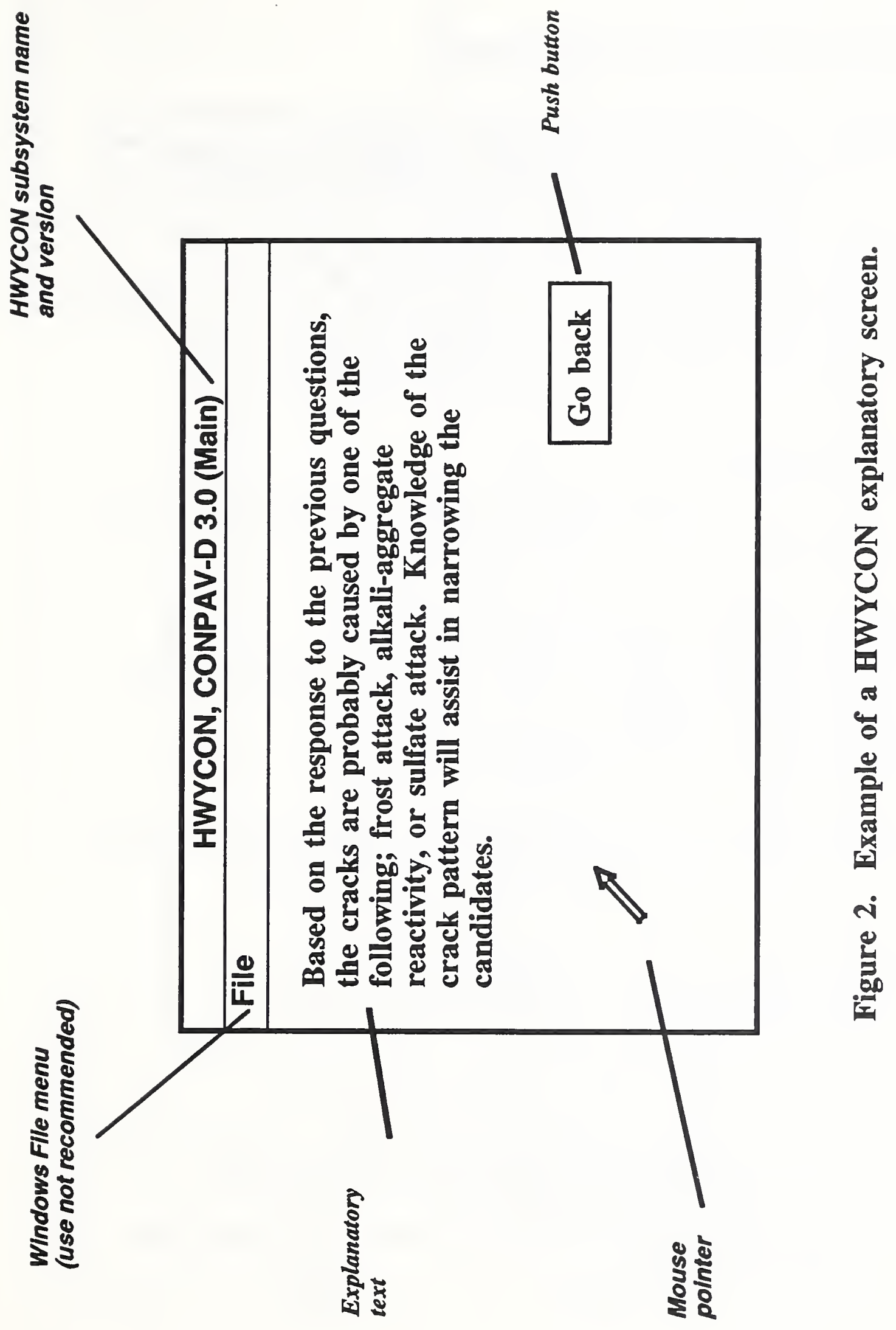




\subsubsection{HWYCON Conclusions and Recommendations}

When the user has input enough information, conclusion or recommendation screen will be displayed. Additional information in the form of explanations, table, or references may also be available, and can be selected using one of the push buttons provided in the screen. These push buttons contain information that describes tests to perform to confirm the systems diagnosis, bibliographic references, explanatory information, or provides the user with the ability to select another HWYCON subsystem. In many cases, the information contained in the HWYCON screens extends beyond the screens vertical limits. The user may "scroll" through the text by placing the mouse pointer over the up and down cursor in the scroll bar to continue reading the remaining text or review previously displayed text. Figure 3 provides an example of a CONPAV-D conclusion screen.

\subsubsection{Completing a session}

When the user has reviewed the conclusion screen several push button options are available. These include:

1. restart the subsystem

2. repeat the same session with different user input

3. continue processing (if multiple responses were selected in previous screens)

4. view bibliographic references

5. view explanatory information

6. activate another HWYCON knowledge topic

7. quit the session.

Not all conclusion and recommendation screens contain every option listed above. Only those that are relevant to the knowledge being described are displayed.

\section{DISTRIBUTION PACKAGE AND REQUIREMENTS FOR USING HWYCON}

The HWYCON distribution package includes the following items:

HWYCON Requirements and Installation Guide (NIST Internal Report 5190)

Highway Concrete Expert System User Reference and Enhancement

Guide (NIST Internal Report 5184)

HWYCON User Distribution Diskette Set containing the following diskettes:

1. Run-only system disk

2. CONPAV-D knowledge disk 


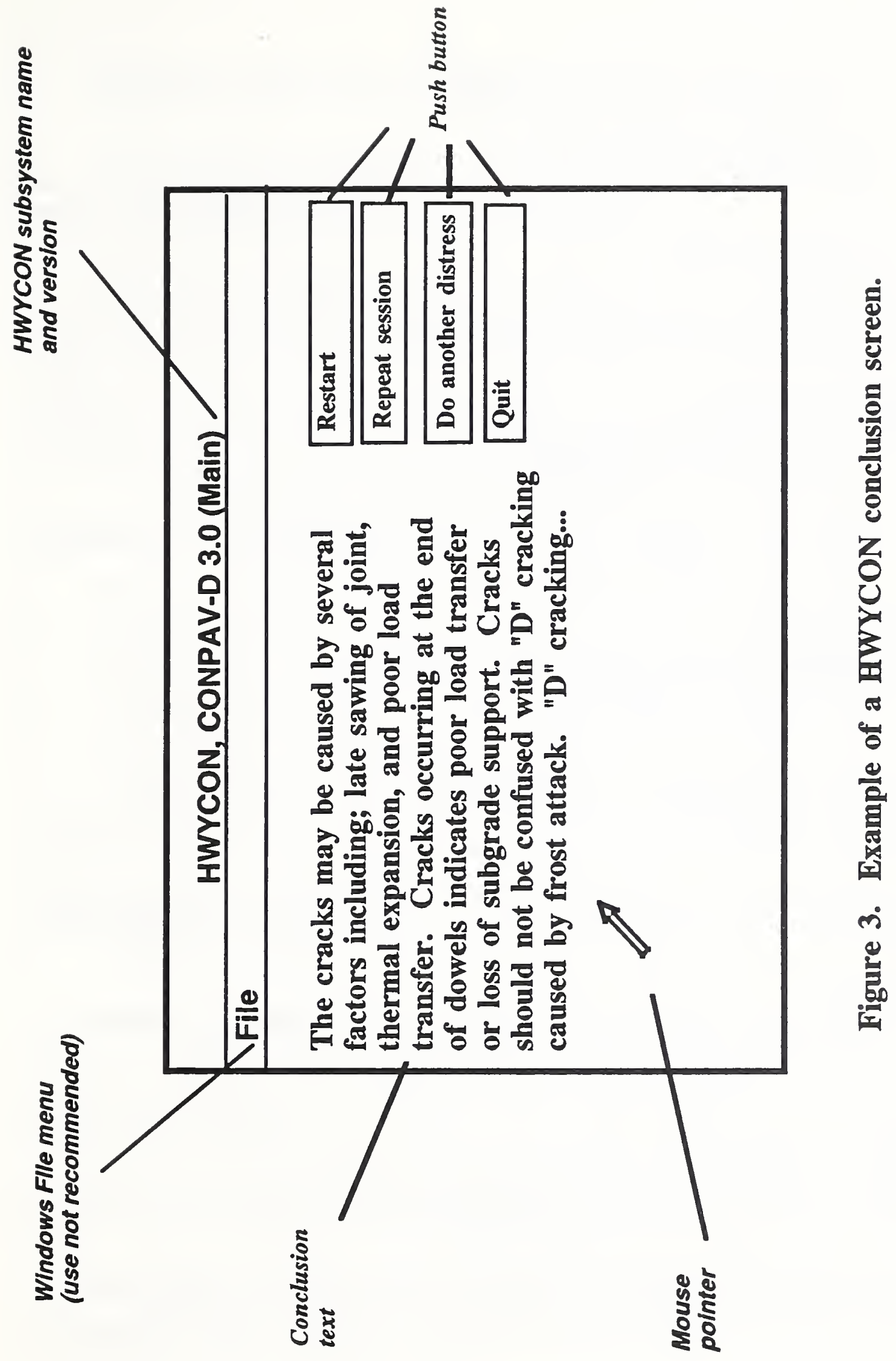


3. CONSTRUC-D knowledge disk \#1

4. CONSTRUC-D knowledge disk \#2

5. CONMAT knowledge disk

6. CONPAV-R knowledge disk

The contents of the knowledge disks are listed in this document in the section titled "HWYCON Knowledge Topics".

To use HWYCON you must have installed a computer system configured to be compatible with the hardware and software described below:

\section{Computer Hardware}

IBM or compatible desk top or portable computer

- at least 2 mega bytes of memory

- a hard disk drive with at least 15 mega bytes of available disk space

- a $5.25^{\prime \prime}$ or $3.5^{\prime \prime}$ floppy disk drive

- EGA, VGA or Super VGA graphics adapter and monitor

- Microsoft compatible mouse device

\section{Computer Software}

DOS operating system, version 3.0 or later [Compaq 1987]

Microsoft Windows, version 3.0 only

To install and use the HWYCON system, you should have a working knowledge of the Microsoft Windows, Program Manager. Information on this topic is covered in the Windows User's Guide [Microsoft 1990].

Although HWYCON can be operated using a keyboard, it is not recommended because it is a very tedious operation. Instead, the use of a pointing device (such as a mouse) is recommended.

To use HWYCON, it is assumed that the user has a basic knowledge of the operation of the recommended computer system and its operating commands. These include:

- power on and booting procedures

- procedures and commands for using floppy diskettes, and hard disk drives

- operation of a mouse pointing device

- basic commands for Windows 3.0 (e.g. starting, selecting windows, selecting program icons, and exiting Windows)

Detailed instructions for these operating procedures are described in the documentation that was supplied with your computer hardware and software. 


\section{INSTALLATION PROCEDURE}

If you currently have previous versions of HWYCON sub-systems installed, you should remove them from your hard disk. To accomplish this, do the procedures in Section 7, "De-installing previous HWYCON sub-systems".

The installation of HWYCON subsystems, CONPAV-D, CONSTRUC-D, CONMAT, and CONPAV-R involves installing the Level5 Run-Only program disk, and the HWYCON knowledge disks. Each diskette requires a separate install procedure. The system will only operate on a hard disk. You may install HWYCON on hard drives or partitions with names other than "C:". However, you must install both the HWYCON knowledge disks and the system disk on the same drive or partition. There should be a minimum of 15 million bytes of free disk storage available on the hard disk to install all of the HWYCON subsystems. The instructions below describe the installation commands.

\section{Installing the Level5 Run-Only Disk}

1. Turn on the computer.

2. If Microsoft Windows is running, terminate the program and return to the DOS prompt.

3. Insert the "Disk 1 - Run-Only System Disk diskette into a 3.5" disk drive.

4. At the DOS prompt, change the prompt to the drive containing Disk 1. For example, if you inserted Disk 1 in your A drive, type A: and press enter.

5. Type install and depress the ENTER key.

When you depress the ENTER key, the following message appears:

Make sure "Disk 1 - Run-Only System Disk" is in the drive. Depress the Enter key and proceed:

6. Depress the ENTER key.

When you depress the ENTER key, the following message appears:

Enter the destination directory for LEVEL5 OBJECT Run-Only files. To select the default c: $\mid$ L5RO, press <Enter>:

5. To install the default directory, depress the ENTER key. The installation task will create the c:l15ro directory on your hard disk if it does not already exist.

When you depress the ENTER key the following message may appear:

The specified directory c:1/5ro does not exist. Install will create it and LEVEL5 OBJECT Run-Only files will be installed in c:|l5ro. 
Do you want to proceed $(Y / N)$ ?

6. Type $\mathbf{Y}$ and depress the ENTER key.

This message appears:

Extracting Run-Only files to C:1l5ro.

You will see the Disk 1 Run-Only files being installed. When the installation is complete, this message appears:

\section{Installation complete.}

You are now ready to install the HWYCON knowledge diskettes.

\section{Installing the CONPAV-D, CONSTRUC-D, CONMAT, and CONPAV-R Knowledge}

Disks

1. Remove the "Disk 1 - Run-Only System Disk" from either drive A: or B:, and insert the "CONPAV-D Knowledge disk".

2. At the DOS prompt, type either a: or $\mathbf{b}$ : then install followed by the floppy disk drive identification, then the hard disk drive identification.

For example, b:install b: c:, then press the "ENTER" key.

3. Using the disk drive identifiers specified in step 2 above, install the CONSTRUC-D knowledge Disks \#1, \#2, and \#3.

4. Using the disk drive identifiers specified in step 2 above, install the CONMAT knowledge disk.

5. Using the disk drive identifiers specified in step 2 above, install the CONPAV-R knowledge disk

The files on the HWYCON program and knowledge disks will be installed in the hard disk drive specified in step 2, above. The sub-directory names shown below will be created on the drive.

Note! The Run-Only System Disk and CONPAV-D Knowledge Disk files must be installed in the default directories, as specified below: 
Level5 Run-Only program files $=\mid \mathrm{L} 5 \mathrm{RO} \backslash$

CONPAV-D knowledge files $=\langle$ hwy con $\backslash$ cpd $\backslash$

CONSTRUC-D knowledge files = $\backslash$ hwy con $\backslash$ csd $\backslash$

CONMAT knowledge files $=\mid$ hwycon $|c m a t|$

CONPAV-R knowledge files $=\mid$ hwycon $|c p r|$

\section{Creating The HWYCON Window and Icons}

The HWYCON subsystems can be activated from a "window" which makes the operation of the programs more simple. The following procedures can be used to create the HWYCON window and program icons.

\section{Establishing the HWYCON group window:}

- start Windows

- click on the Program Manager, Main Window

- click on "File"

- click on "New"

- click on "Program Group"

- click on "ok"

- type: "HWYCON Expert System" (omitting the " (quote) characters)

- click on the "Group File" property box

- type: "HWYCON.GRP" (omitting the " (quote) characters)

- click on "ok"

The empty "HWYCON Expert System" window will appear.

\section{Establishing icons for CONPAV-D, CONSTRUC-D, CONMAT, and CONPAV-R:}

- click on "File"

- click on "new"

- click on "ok"

- type: "CONPAV-D" (omitting the " (quote) characters)

- click on the "Command Line" property box

- type: "c:LL5ROLL5RO.exe c: Lhwyconlcpdlcpdmain.app" (omitting the " (quote) characters...Note that a space appears between "exe" and "c:")

- click on "ok"

- click on "File"

- click on "New"

- click on "ok"

- type: "CONSTRUC-D (Bridge Decks)" (omitting the " (quote) characters)

- click on the "Command Line" property box

- type: "c:LL5ROLLRRO.exe c: Lhwy conlcsdlcsdmain.app" (omitting the " (quote) characters...Note that a space appears 
- click on "ok"

- click on "File"

- click on "New"

- click on "ok"

- type: "CONSTRUC-D (Structures)" (omitting the " (quote) characters)

- click on the "Command Line" property box

- type: "c:IL5ROULRO.exe c: Ihwy conlcsdlcsdst.app"

(omitting the " (quote) characters...Note that a space appears

between "exe" and "c:")

- click on "ok"

- click on "File:

- click on "New"

- click on "ok"

- type: "CONMAT" (omitting the " (quote) characters)

- click on the "Command Line" property box

- type: "c:ULROL5RO.EXE c: Ihwy con lcmatlcmatmain.app"

(omitting the" (quote) characters... Note that a space appears

between the "exe" and "c:")

- click on "ok"

- click on "File:

- click on "New"

- click on "ok"

- type: "CONPAV-R" (omitting the " (quote) characters)

- click on the "Command Line" property box

- type: "c:IL5ROULRO.EXE c: lhwyconlcprlconpavr.app"

(omitting the " (quote) characters...Note that a space appears between the "exe" and "c:")

- click on "ok"

The icons may overlap each other in the Window. If so, click on an overlapping icon and "drag" it to a new location. To record the new location, you must exit Windows with the "Save Changes" option on.

\section{DE-INSTALLING PREVIOUS VERSIONS OF HWYCON}

The following commands are may be omitted:

- start Windows and select the Main Window

- click once on the "CONPAV-D" icon

- click on "File"

- click on "Delete"

- click on "Yes" to delete the CONPAV-D icon

- exit to DOS, click on the "DOS" icon from the Main Window 
The following commands are required:

- delete all files from lhwyconlcpd

- remove the directory \hwyconlcpd

- delete all files from \hwyconlcsd

- remove the directory lhwyconlcsdl

- delete all files from thwycon \cmat

- remove the directory \hwycon \cmat

- delete all files from \hwyconlcprl

- remove the directory \hwyconlcprl

- return to Windows, type: "exit"

\section{PROBLEMS AND INCOMPATIBILITIES}

\subsection{Windows 3.1 Incompatibility}

HWYCON, version 3.0 is designed to be used with Microsoft Windows, version 3.0. The use of HWYCON, version 3.0 with Microsoft Windows version 3.1 will result in two known problems:

1. When attempting to start another HWYCON subsystem (by double-clicking on an icon), nothing happens. This problem does not always occur. The only way to start another HWYCON subsystem is to restart Windows.

2. Displays have overlapping text. There is no solution to this problem until a new version of the HWYCON system is upgraded for compatibility with Microsoft

The solution to the Microsoft Windows, Version 3.1 incompatibility would require an upgrade to the Level5 Run-Only system software provided with HWYCON, version 3.0. This task would require the purchase of a Level5 Run-Only system, version 2.5 distribution license, and the generation of updated versions of the HWYCON knowledge files. Requests should be made to the organization charged with the distribution of the HWYCON system.

\subsection{Other Problems While Operating HWYCON}

HWYCON was rigorously tested during its development. Many different computer brands and configurations were tested by both the developers and users. Few incompatibilities resulted that were not related to the Windows problem described above. Efforts were made to identify potential compatibility problems that could occur through the use of HWYCON. However, it was not possible to anticipate every variation computer configurations. Those problems that did occur were associated with computer hardware or software malfunctions or improper configuration of DOS or Windows software. It can be 
stated, through experience, and with a high degree of confidence, that if a problem does exist with the installation or operation of HWYCON, that it most likely relates to incompatibility in the software versions, or a machine malfunction. Users should first check to ensure that the proper computer configuration and software versions are correctly installed, as described in Section 5. Generally, if Windows rexecutes without problems, then HWYCON will also.

\section{REFERENCES}

Compaq Computer Corp., MS-DOS Version 3.3 Reference Guide, Compaq Computer Corp., Houston, TX (1987).

Kaetzel, L.J., Clifton, J.R., Snyder, K.A., Klieger, P., Highway Concrete (HWYCON) User Reference and Enhancement Guide, NISTIR 5184, NIST, Gaithersburg, MD (1993).

Microsoft Corp., Microsoft Windows User's Guide, Version 3.0 for the MS-DOS Operating System, Microsoft Corp., Remond, WA (1990). 
APPENDIX A. FIELD CHECKLISTS FOR CONPAV-D AND CONSTRUC-D 



\section{FIELD INSPECTION CHECKLIST \\ HWYCON-CONPAV-D (Jointed Concrete Pavements)}

Place a mark in the appropriate box to indicate conditions observed in the pavement. This information will be needed when operating CONPAV-D.

PAVEMENT TYPE: $\square$ Jointed Reinforced Concrete Pavement (JRCP)

DISTRESS TYPE:

$\square$ Jointed Plain Concrete Pavement (JPCP)

\section{$\square$ CRACKING}

$\square$ At joints, edges and other openings

$\square$ localized near joints

$\square$ random crack pattern

Pattern:

$\square$ single crack having random directions

$\square$ map or bulky

Form closed Patterns:

$\square$ yes

Diameter: $\square<50 \mathrm{~mm} \quad \square=>50 \mathrm{~mm}$

$\square$ no

Appearance of clean break with matching irregularities:

$\square$ yes $\square$ no $\square$ can't tell

Direction:

$\square$ straight

Direction and Appearance:

$\square$ perpendicular and no rust

$\square$ perpendicular with rust

$\square$ diagonal

$\square$ longitudinal

$\square$ closely spaced or map

Spacing:

$\square<10 \mathrm{~mm}$ and darkened

$\square=>10 \mathrm{~mm}$

$\square$ viscous gel present

\section{$\square$ Generally straight crack}

Direction:

$\square$ transverse

$\square$ longitudinal

$\square$ diagonal

$\square$ divides slab in segments

$\square$ diagonal @ 45 degrees to slab edges( 0.2 to 2 meter spacing)

$\square$ transverse cracking regularly spaced 3 meters

$\square$ transverse cracking not regularly spaced

$\square$ longitudinal cracking over rebars in JRCP

$\square$ rust stains present in JRCP

$\square$ long predominantly straight cracks parallel to center in JRCP

$\square$ series of parallel, longitudinal cracks with randomly spaced transverse cracks in JPCP 


\section{CONPAV-D FIELD INSPECTION CHECKLIST (CONTINUED)}

\section{DISTRESS TYPE:}

$\square$ JOINT RELATED DISTRESSES

$\square$ Sealant failure

$\square$ loss of adhesion

$\square$ at $50 \%$ or more of joints

$\square$ at $<50 \%$ of joints

$\square$ loss of cohesion

$\square$ sealant extrusion

\section{Cracking}

Pattern:

$\square$ predominantly straight

$\square$ short, 1-2 meters, no rust

$\square$ perpendicular to joint, with rust

$\square$ parallel to transverse joints

$\square$ closely spaced or map

$\square<10 \mathrm{~mm}$, parallel to joints

$\square$ longitudinal crack

\section{Spalling}

$\square$ associated with cracks

$\square$ localized near joint

\section{Depth:}

$\square$ shallow

$\square$ wedge shaped or tapering toward back and sides

\section{Faulting}

$$
\square \text { extending to or deeper than slab center }
$$

$\square$ at transverse joint

$\square$ at longitudinal joint

$\square$ drainage system present

\section{$\square$ SURFACE DISTRESSES}

\section{$\square$ Spalling}

$\square$ rust stains present

$\square$ popouts

$$
\begin{aligned}
& \square \text { larger than coarse aggregate } \\
& \square \text { much smaller }
\end{aligned}
$$

\section{Scaling}

$\square$ light

$\square$ heavy and on traffic regions

\section{Potholes}

\section{Polishing of Aggregate}




\section{FIELD INSPECTION CHECKLIST \\ HWYCON-CONPAV-D (Continuously Reinforced Concrete Pavements)}

Place a mark in the appropriate box to indicate conditions observed in the pavement. This information will be needed when operating CONPAV-D.

\section{DISTRESS TYPE:}

$\square$ CRACKING

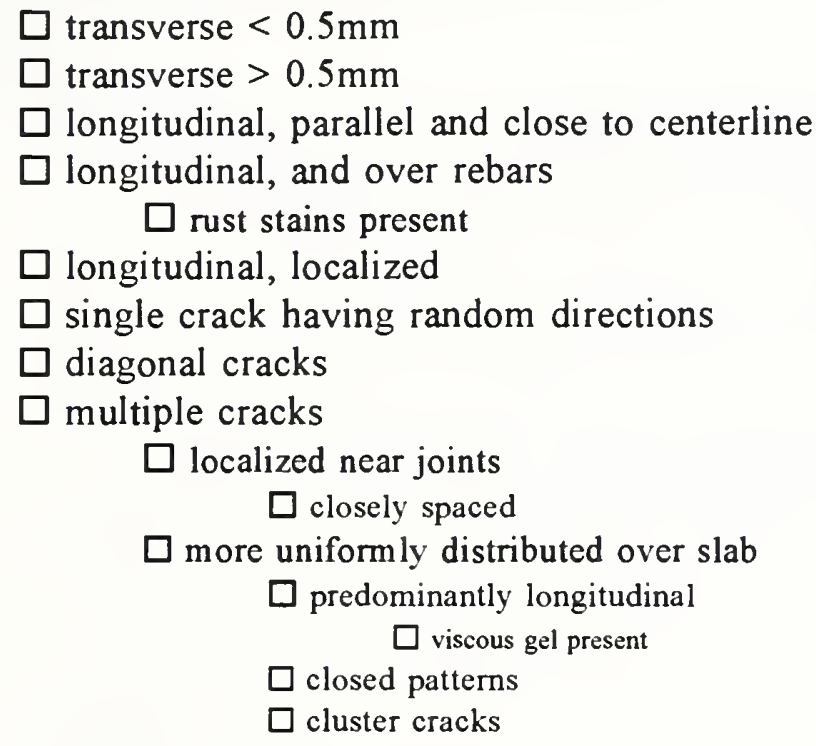

\section{$\square$ JOINT RELATED DISTRESSES}

$\square$ Construction joints

$\square$ spalling present

$\square$ little

$\square$ spalling and/or faulting

$$
\begin{aligned}
& \square \text { spalls deeper than wide } \\
& \square \text { spalls wider than deep }
\end{aligned}
$$

$\square$ Longitudinal joints

$\square$ consists of cracks

$\square$ consists of faulting

$\square$ Lane-shoulder joint 


\section{CONPAV-D FIELD INSPECTION CHECKLIST (CONTINUED)}

$\square$ SPALLING

$\square$ rust stains present

$\square$ popouts

$\square$ around the size of larger coarse aggregate

$\square$ much smaller than the larger coarse aggregate size

\section{$\square$ SCALING}

$\square$ exposed to freezing and deicing salts

$\square$ never exposed to freezing and deicing salts

$\square$ light scaling

$\square$ heavy traffic

\section{$\square$ POTHOLES}

$\square$ POLISHING OF AGGREGATE

\section{EDGE-PUNCHOUT}




\section{FIELD INSPECTION CHECKLIST \\ HWYCON-CONSTRUC-D (Bridge Decks)}

Place a mark in the appropriate box to indicate conditions observed in the pavement. This information will be needed when operating CONSTRUC-D.

Construction Type:

$\square$ concrete

$\square$ concrete and steel

Distress Type:

\section{CRACKING}

$\square$ longitudinal

$\square$ over rebars

$\square$ rust stains present in crack area

$\square$ corrosion of rebars

$\square$ cracks extend deeper than rebars, through slab

transverse

$\square$ pass through aggregate

$\square$ around aggregate

$\square$ around then pass through aggregate

diagonal

$\square$ at acute-angle corner

$\square$ at a single column pier

random

pattern or map

$\square$ patterns generally $<50 \mathrm{~mm}$ in diameter

$\square$ larger than $50 \mathrm{~mm}$ in diameter

$\square$ predominantly longitudinal

$\square$ closed map

$\square$ exhibit disintegration

\section{SPALLING AND POPOUTS}

$\square$ rust stains or rusted rebars present

$\square$ general spalling

$\square$ popouts

$\square$ around the size of larger coarse aggregate

$\square$ much smaller

\section{SCALING}

POLISHING OF AGgREGATE 



\section{FIELD INSPECTION CHECKLIST HWYCON-CONSTRUC-D (Structure Submembers)}

Place a mark in the appropriate box to indicate conditions observed in the pavement. This information will be needed when operating CONSTRUC-D.

\section{SUBMEMBER:}

$\square$ pier

$\square$ column

$\square$ parapet wall

$\square$ other

ORIENTATION:

horizontal

$\square$ vertical

DISTRESS TYPE:

CRACKING

longitudinal or transverse

$\square$ over reinforcing steel

$\square$ propagate horizontally

$\square$ separation of column from beam or similar element

propagate vertically

$\square$ crack spacing at least 3 meters

horizontal crack connected somewhat by parallel cracks

cracks at joints or edges

$\square$ closely spaced $<10 \mathrm{~mm}$ and darkened

$\square$ propagate in random direction from joint

series of random (map or pattern)

$\square$ form closed patterns

$\square$ crack horizontal $3-5 \mathrm{~mm}$ wide

$\square$ crack vertical $<1 \mathrm{~mm}$ wide

$\square$ exposed to soil or sea water

$\square$ evidence of overall expansion

$\square$ disintegration of the top surface with map cracking below

$\square$ scaling and " $\mathrm{D}$ " cracking present

diagonal cracks

$\square$ propagate from opening in wall

$\square$ propagate from rigid inclusion to slab

random cracks

\section{SPALLING AND POPOUTS}

rust stain or rusted rebars present

popouts

$\square$ around the size of the larger coarse aggregate

much smaller than larger coarse aggregate 


\section{CONSTRUC-D (STRUCTURE SUBMEMBERS) FIELD INSPECTION CHECKLIST (CONTINUED)}

\section{口 DISINTEGRATION AND SCALING}

$\square$ distress observed where concrete is exposed to soil or in splash zone

$\square$ disintegration of top surface with map cracking below

$\square$ light scaling 

